AgnieszKa GromKowsKa-MeLosiK

Uniwersytet im. Adama Mickiewicza

w Poznaniu

\title{
CZERWONY KAPTUREK. KOBIECOŚĆ (NIE)UJAWNIONA - INTERPRETACYJNE PROWOKACJE
}

\begin{abstract}
Aвstract. Gromkowska-Melosik Agnieszka, Czerwony Kapturek. Kobiecość (nie)ujawniona - interpretacyjne prowokacje [Red Riding Hood. (Un)revealed Femininity - Interpretative Provocations]. Studia Edukacyjne nr 45, 2017, Poznań 2017, pp. 29-38. Adam Mickiewicz University Press. ISSN 1233-6688. DOI: $10.14746 /$ se.2017.45.3

The author of the article reconstructs the various concepts of femininity in the fable Red Riding Hood. The main thesis is related to conviction that fables including Red Riding Hood are the field of specific crystallization of culture uncertainity. In the case of Red Riding Hood competing interpretations of meanings are deconstructed. One can give here as an example the feminist understanding of Red Riding Hood, postmodern approach to this fascinating heroine and power girl related thinking, as well as psychoanalytic concepts. So in the seemingly naïve and banal fable various version of femininity and feminine sexuality can be discovered.
\end{abstract}

Key words: Red Riding Hood, constructions of femininity, interpretation, fables, open meanings

Mała dziewczynka w czerwonej pelerynce i kapturku wędruje przez las po to, aby zanieść chorej babci smakołyki ukryte w wiklinowym koszyczku. Nieco infantylna i zagubiona spotyka wilka, który chce ją zwieść i zjeść... ${ }^{1}$ A może inaczej: piękna kobieta w czerwonej cudownej sukni i pelerynie z kapturem od Chanel włamuje się do skarbca pełnego flakonów legendarnego No. 5, strzeżonego przez sforę wilków. Onieśmielone jej urodą tracą swoją dzikość i przysiadają niczym tresowane psy... O Od niczego nieświadomej

${ }^{1}$ Jest to wersja z mojego dzieciństwa, zapewne znana doskonale większości dzieci.

2 Reklama Chanel No. 5 z udziałem Estelli Warren, adres internetowy: https://www. youtube.com/watch?v=z5MHa1CtNEI 
małej i uległej dziewczynki ${ }^{3}$ do zmysłowej i świadomej swojej seksualności kobiety. Oto historia, a raczej szereg historii jednej z najbardziej znanych bajek na świecie, o szeregu wersji, z których każda ma inne zakończenie, każda zawiera inne znaczenia, a nawet ma odmienną narrację.

Czerwony Kapturek wpisuje się w tę sekwencję bajek, które, podobnie jak Królewna Śnieżka, Kopciuszek, czy Królowa Śniegu, odzwierciedlają różnorodne niepokoje nurtujące kulturę Zachodu. Można przy tym założyć, że podobnie jak to miało miejsce w przeszłości, tak i w kolejnych dekadach XXI wieku będzie ona postrzegana przez pryzmat wyłaniających się kolejnych niepokojów. Jest więc w tym sensie uniwersalna, że jej główny motyw może być przywoływany $\mathrm{w}$ różnorodnych, niekiedy sprzecznych, kontekstach. Dodam, że właśnie bajki stanowią jedną z tych przestrzeni kulturowych, w których to, czego nie można powiedzieć wprost, zostaje zrekonstruowane i zreinterpretowane oraz ucieleśnione i utożsamione poprzez występujących w nich bohaterów oraz fabułę. Ta ostatnia może być podatna na niekończące się interpretacje odkrywające zrepresjonowane przez kulturę formy, czy to seksualności czy władzy w relacjach społecznych i personalnych. W przypadku Czerwonego Kapturka kluczową rolę odgrywają te interpretacje i ambiwalencje o charakterze utraconej niewinności, a niekiedy wprost narzucane tekstowi bajki znaczenia o charakterze seksualnym.

Czerwony Kapturek ma ponad pięć milionów adresów w popularnej internetowej wyszukiwarce Google i jest najczęściej analizowaną, opisywaną i rekonstruowaną bohaterką w literaturze. Została przetłumaczona na niemal wszystkie języki świata, a o jej uniwersalności świadczy fakt międzynarodowej kariery - wraz z nowymi odczytaniami, często w kontekście lokalnych kultur ${ }^{4}$. Analizująca fenomen Czerwonego Kapturka Sandra Beckett uznaje ją za posiadającą " niewyczerpane możliwości” reinterpretacji oraz niebywały potencjał satyryczny ${ }^{5}$. Jack Zipes nazywa ją „najpopularniejszą i bez wątpienia najbardziej prowokacyjną bajką w zachodnim świecie" ${ }^{\prime 6}$.

${ }^{3}$ Tę właśnie wersję Królewny Śnieżki, Kopciuszka, Roszpunki i Czerwonego Kapturka odtwarzają oficjalne przekazy medialne skierowane do dzieci, w których pojawiają się „kulturowe markery akceptowanej dziewczęcości i dojrzewania (...) szczególnie w wersjach proponowanych przez Disneya, które składają się z takich atrybutów, jak: niewinność, dziecięce ciała i umysły, najczęściej pozbawione drugorzędnych cech płciowych wyznaczających kobiecość, (...), a przede wszystkim czystość serca i piękno, które to cechy razem są wykorzystywane aby tworzyć i wzmacniać jednoznaczne pojęcie płci kulturowej kobiet i przeznaczonych dla nich ról płciowych". Hasło: Fairly Tales. Modern, w: Girl Culture. An Encyclopedia, vol. 1, Ed. C. Mitchell, J. Reid-Walsh, London, s. 281.

${ }^{4}$ Dla Japończyków Czerwony Kapturek jest jedną z ikon kultury Zachodu. Stanowi dla nich „kulturowy marker”, który konstytuuje dla japońskich artystów wizerunek Europy; Jacob and Wilhelm Grimm, Little Red Cap, [w:] Little Ride Riding Hood. A Casebook, Ed. A. Dundes, 1989, s. 8.

${ }^{5}$ S.L. Beckett, Recycling Red Riding Hood, New York 2002, s. xv

${ }^{6}$ J. Zipes, The Trials and Tribulations of Little Red Riding Hood, New York 1993, s. 343. 
Z kolei Margaret Gunning upatruje atrakcyjności bajki o Czerwonym Kapturku w jego seksualnym niebezpieczeństwie i trudnej do oparcia się pokusie tego, co zakazane. Nazywa go ona także "marzeniem feministek"7, szczególnie w kontekście przekroczenia przez główne postacie tradycyjnych ról płciowych. Nie sposób także nie zgodzić się z Catherine Orenstein, zdaniem której fenomen Czerwonego Kapturka jest związany z „ucieleśnianiem przez niego złożonych i fundamentalnych ludzkich niepokojów" ${ }^{8}$.

Liczba wersji Czerwonego Kapturka jest tak duża, że Sandra Beckett używa w tytule swojej książki w odniesieniu do kolejnych wersji określenia „recyklingu". W swojej analizie odnalazła ona zarówno w wersjach zawierających się w kulturze wysokiej, jak i niskiej następujące sposoby ekspresji fabuły bajki: „humorystyczną, poważną, tragiczną, ironiczną, cyniczną, rozrywkową, nonsensowną" ${ }^{\prime 9}$. Autorka ta twierdzi także, za Carlesem Cano, iż właśnie ta bajka może bardzo łatwo przekształcić się w historię szpiegowską, detektywistyczną, horrorystyczną, przygodową lub pozostać klasyczną bajką ${ }^{10}$. Nawiązując do teorii postmodernistycznej, nazywa ona kolejne wersje tej bajki „ekstremalnie ekscytującymi i innowacyjnymi, estetycznymi eksperymentami". Również postać Czerwonego Kapturka ulega w różnych wersjach radykalnym transformacjom, staje się ona córką chłopa albo miejską dziewczyną, gwiazdą rocka albo aktorką, superbohaterką, postacią z komiksu, namiętną uwodzicielką. Z postmodernistycznej perspektywy bajka ta staje się plastycznym materiałem bez żadnej ostatecznej, definitywnej wersji ${ }^{11}$. W przypadku Czerwonego Kapturka mamy bez wątpienia z ewolucją mitu ${ }^{12}$.

Pierwsza, przekazywana ustnie ${ }^{13}$, francuska wersja Czerwonego Kapturka nosiła tytuł The Story of Grandmother (Opowieść Babci) ${ }^{14}$, a jej bohaterką była wiejska dziewczyna, świadoma swojej seksualności, która potrafi sama uwolnić się od wilka za pomocą przemyślnego triku. Oto przed pój-

${ }^{7}$ M. Gunning, Not Before Bed, https://www.januarymagazine.com/artcult/littlereduncloaked.html

${ }^{8}$ C. Orenstein, Little Red Riding Hood Uncloaked: Sex, Morality, and the Evolution of a Fairy Tale, New York 2002, s. 7-8.

9 S.L. Beckett, Recycling, s. 20.

${ }^{10}$ Tamże.

11 Tamże.

${ }^{12}$ G. Husing, "Is Little Riding Hood" a Myth? [w:] Little Ride Riding Hood. A Casebook, Ed. A. Dundes, s. 67.

${ }^{13}$ Niektórzy krytycy zarzucają akademickim interpretacjom Czerwonego Kapturka, że odnoszą się jedynie do wersji upowszechnionej przez Perraulta i Braci Grimm. Twierdzą oni, że istnieją "autentyczne oralne wersje bajki, które ujawniają ważne, inne szczegóły”, A. Dundes, Introduction, [w:] Little Red Riding Hood, s. ix.

${ }^{14}$ Jedną z tych wersji zamieszczono w: P. Delarue, The Story of Grandmother, [w:] Tamże, s. 13. 
ściem z nim do łóżka, rozbiera się i prosi go o możliwość załatwienia swojej potrzeby fizjologicznej na świeżym powietrzu, dzięki czemu udaje się jej uciec $^{15}$.

Najbardziej klasyczne wersje Czerwonego Kapturka są dwie: ta Charlesa Perraulta Le Petit Chaperon Rouge (francuskojęzyczna wydana w 1697) oraz autorstwa braci Jacoba i Wilhelma Grimm Rottkapchen (niemieckojęzyczna wydana w 1812). W pierwszej z nich Czerwony Kapturek jest małą naiwną dziewczynką, którą matka wysyła do chorej babci. Droga wiedzie przez las, w którym główna bohaterka wdaje się w rozmowę z wilkiem. Ten, korzystając z naiwności Czerwonego Kapturka, wskazuje mu dłuższą drogę do domu babci. Wilk trafia do domku babci przed dziewczynką i zjada babcię, a następnie przebiera się w jej ubranie i kładzie do łóżka. To przyczynia się do tragicznego końca - wilk zwabia Czerwonego Kapturka do łóżka, a w finale pożera ją.

Czerwony Kapturek Charlesa Perraulta został napisany dla arystokracji francuskiej na dworze Ludwika XIV. Zawierał dość oczywistą aluzję do strzeżenia przez nie swojej cnoty i trzymania się z dala od mężczyzn, którzy uwodzą niewinne i nieświadome dziewczęta:

Morał stąd płynie - proszę słuchać, urocze wdzięczne me dziewuszki, że obcych ludzi pogaduszki należy puszczać mimo ucha. (...) Radzę wam zapamiętać, że jest podstępny wilk niektóry: ukrywa wilcze swe pazury by słodkim słówkiem zwieść dziewczęta ${ }^{16}$.

Jedno z podstawowych, zawartych w bajce przesłań moralnych odnosi się więc do przekonania, że młode dziewczęta powinny unikać niebezpiecznych miejsc i nieznajomych. Jak ujął to sam Charles Perrault „z tej bajki można się nauczyć, że dzieci, szczególnie małe, miłe, grzeczne i dobrze wykarmione nie powinny słuchać pewnego rodzaju mężczyzn"17.

W drugiej wersji, autorstwa braci Grimm, opowieść ma podobny przebieg aż do momentu, kiedy w chatce babci pojawia się myśliwy, który rozpruwa wilkowi brzuch i wyjmuje z niego babcię i dziewczynkę. W brzuchu wilka zaszywa kamienie, które przyczyniają się do jego śmierci. To oczywiście wersje klasyczne, które stały się pierwowzorem do mniej lub bardziej swobodnego potraktowania tematu.

Jedna $\mathrm{z}$ francuskich wersji Czerwonego Kapturka zawiera istotny motyw wyboru właściwej drogi przez główną bohaterkę. Oferowany przez Wilka wybór obejmuje trudną drogę igieł (metafora ta odwołuje się do pracochłonnej czynności zszywania ze sobą kawałków materiału, a więc drogi pełnej

\footnotetext{
${ }^{15}$ M. Tartar, The Hard Facts of the Grimm's Fairy Tale, New Jersey 2003, s. 199.

${ }^{16}$ Ch. Perrault, Bajki Babci Gąski, przekł. H. Januszewska, Wrocław 1993.

${ }^{17}$ M. Tatar, The Hard Facts of the Grimm's Fairy Tales, s. 39.
} 
obowiązków) lub łatwą i przyjemną drogę szpilek (metafora spinania kawałków materiału w sposób szybki i niepracochłonny, a zatem drogi szybkiej przyjemności). Kapturek wybiera drogę szpilek - co stanowi metaforę łatwego i przyjemnego życia pozbawionego obowiązków, ale też oznacza zboczenie z właściwej dla młodych dziewcząt drogi cnoty i powinności ${ }^{18}$.

Interesującą odmianą Czerwonego Kapturka jest poemat napisany w 1827 roku przez Jamesa N. Barkera, w której babcia opowiada historię Czerwonego Kapturka swoim wnuczkom ${ }^{19}$. Wilk jest tu ukazany jako alegoria mężczyzny-uwodziciela, a nawet miłości, która jest zwodnicza i należy jej unikać, ponieważ prowadzi do złego końca. Babcia tłumaczy wnuczkom przesłanie bajki, które, jak uważa, nie jest oczywiste dla małych dziewczynek, które zbyt dosłownie traktując tę opowieść, nie są w stanie zrozumieć jego istoty.

Niewinne dzieci czytają tę opowieść dosłownie, ale starsze i mądrzejsze potrafią odczytać morał. Wilk, którego musicie się strzec to miłość. (...) Miłość to mężczyzna, jak mówią piosenki, bardzo zuchwały ${ }^{20}$.

Dziewczynki przytakują, że nigdy nie będą podejmować rozmów z nieznajomymi i potencjalnie niebezpiecznymi (seksualnie) mężczyznami. Jednak zdziwione faktem, że wilk pożera najpierw babcię, zadają retoryczne w swej istocie pytanie: czy Babcia również może zostać zwiedziona przez wilka? (wnuczka pyta dosłownie: „Czy wszystkie babcie jako pierwsze zostały pożarte przez miłość?”, na co babcia odpowiada: „Robi się zimno, chodźmy już bezczelna smarkulo") ${ }^{21}$.

Najbardziej współczesna wersja Czerwonego Kapturka, autorstwa Jamesa Grovera Thurbera, to dziewczyna uosabiająca ideę power girl ${ }^{22}$, odwołującej się do jednej z form popkulturowej emancypacji kobiet, bez wahania strzelająca do wilka z pistoletu ukrytego w koszyczku. Ta wersja kończy się znakomitą puentą: „nie jest łatwo ogłupić dzisiejsze młode dziewczyny, jak to bywało w przeszłości" 23 .

${ }_{18}$ B. Bettelheim, The Uses of Enchantment. The Meanings and Importance of Fairy Tales, London 1991, s. 171.

${ }^{19}$ J.N. Baker, Little Red Riding Hood, 1827, [w:] W.E. Burton, The Cyclopedia of Wit and Humor, 1858, s. 66, wersja zdigitalizowana: https://archive.org/stream/in.ernet. dli.2015.60393/2015.60393.The-Cyclopaedia-Of-Wit-And-Humor-Volume-I\#page/n95/mode/2up

${ }^{20}$ Tamże.

${ }^{21}$ Tamże.

${ }^{22}$ Szerzej na temat idei power girl: A. Gromkowska-Melosik, Power Girl i kontrowersje wokót (pop)kulturowej emancypacji kobiet wspótczesnych, [w:] Kultura popularna. Konteksty teoretyczne i spoteczno-kulturowe, red. A. Gromkowska-Melosik, Z. Melosik, Kraków 2010, s. 205-230.

${ }^{23}$ J. Grover Thurber, The Little Girl and the Wolf, Otago German Studies, 1998, 10, adres internetowy: https://otagogermanstudies.otago.ac.nz/ogs/issue/view/13 
Z kolei, w rymowanej interpretacji brytyjskiego pisarza Roalda Dahla (Little Red Riding Hood and the Woolf ${ }^{24}$ ), Czerwony Kapturek z uśmiechem wyciąga pistolet z majtek i mrużąc oko zabija wilka kilkoma strzałami w głowę, a kilka tygodni później można ją zobaczyć jak dumnie nosi futro z wilka.

Krytycy podkreślają, że w bajce o Czerwonym Kapturku nie jest ważne tylko słowo, ale jest to bajka stricte wizualna (powstają nawet wersje wyłącznie obrazkowe). Czerwień stanowi kod dostępu (password), który „daje czytelnikowi dostęp do wizerunku". Autorka idzie jeszcze dalej - uważa, że czerwony kapturek jest niczym „otwarty sezam, który dostarcza czytelnikom klucza do enigmatycznej gry odczytywania" ${ }^{25}$.

Nieodłącznie kojarzona z Czerwonym Kapturkiem czerwień pelerynki i nakrycia głowy dziewczynki została jej podarowana przez Ch. Perraulta, który bez wątpienia był świadomy symboliki tego koloru. Jak zauważa Sandra L. Beckett, synekdocha - czyli użycie jedynie fragmentu stroju dla opisu całości postaci, jest zabiegiem uprzedmiatawiającym dziewczynkę. Kolor ten ma bez wątpienia seksualne konotacje ${ }^{26}$.

Z kolei, zdaniem Bruno Bettelheima:

czerwony jest kolorem gwałtownych emocji, a w szczególności seksualnych. Stąd czerwony kapturek podarowany dziewczynce przez matkę może być symbolem przedwczesnej przemiany w seksualnie atrakcyjną (...) zbyt małą, aby poradzić sobie z tym, do czego jego noszenie zaprasza.

Dalej pisze on o „regresywnym doświadczeniu niedojrzałej seksualności”27.

Czerwony Kapturek od wielu lat jest poddawany szeregu analizom i interpretacjom. I choć Mały Czerwony Kapturek z klasycznych wersji wydaje się niewinną bajką dla dzieci, uczącą posłuszeństwa wobec dorosłych i niesłuchania porad obcych, dominujące interpretacje odnoszą się do seksualności kobiecej i męskiej. Nie bez znaczenia jest fakt, iż francuski idiom utraty dziewictwa to elle avoit vu le loup (dosłownie: ona widziała wilka) ${ }^{28}$, a w języku angielskim określenia „wilk” używa się w stosunku do uwodzicieli lady killers $^{29}$. W wersji Czerwonego Kapturka napisanej przez chilijską poet-

${ }^{24}$ R. Dahl, Little Red Riding Hood and the Woolf, adres internetowy: https:/ / ace.home.xs4all. nl/Literaria/Txt-Dahl.html

${ }^{25}$ S.L. Beckett, Recycling, s. 5.

${ }^{26}$ S.L. Beckett, Red Riding Hood for All Ages: A Fairy-tale Icon in Cross-cultural Contexts, Detroit 2008, s. 45.

${ }^{27}$ B. Bettelheim, Little Red Cap and the Pubertal Girl, [w:] Little Red Riding Hood: A Casebook, Ed. A. Dundes, Madison, WI: 1989, s. 173.

${ }_{28}$ A. Carruthers, Little Red Riding Hood - And Others Girls Who Hot Lost in the Woods, Warwickshire 2015 - wykorzystano przedruk książki bez stron.

${ }^{29}$ S.L. Beckett, Red Riding Hood for All Ages, s. 13. 
kę Gabrielę Mistral w 1924 roku występują w sposób bardzo śmiały, jak na przedwojenną obyczajowość, aluzje do uwiedzenia małego Kapturka przez doświadczonego Wilka:

I wchodzi bez wahania. Pachnie lasem cała, w dłoniach trzyma gałązki kwitnącego ziela. -Postaw ciasto przy łóżku. Choć, ogrzej mnie, mała. I Kapturek usłuchał czułego wezwania (...) Miły dotyk jej ciała rozszerza mu ślepia, przerażenie Kapturka mocno go podnieca (...) I bestia atakuje, ostra sierść kaleczy drobne ciało tak miękkie jak runo owieczki. Miażdżą mięśnie, kosteczki te szczęki mordercze i serce wysysają niczym miąższ wisienki ${ }^{30}$.

Zdaniem B. Bettelheima, posłuszne wejście Czerwonego Kapturka do łóżka, w którym leży wilk świadczy nie tylko o naiwności dziewczynki, ale może być też znakiem jej ciekawości i fascynacji wilkiem, a w konsekwencji - pragnienia bycia uwiedzioną. W ten sposób naiwna dziewczynka staje się "kobietą upadłą" ${ }^{31}$. Takie konotacje zdaje się zawierać wiersz Anny Marii Shua, zatytułowany „La sueñera” (Marzycielka), w którym Czerwony Kapturek tęskni za wilkiem pragnąc, aby przyszedł: „godziny uciekają, a wilk nie przychodzi. Co takiego miała moja babcia, czego ja nie mam?"32. Czy Kapturek staje się tutaj prowokatorką, która z upodobaniem wciela się $\mathrm{w}$ rolę obiektu seksualnego?

Jedną z głównych ram nadawanych bajce o Czerwonym Kapturku jest rama uwiedzenia niewinnego dziecka. Nawiązuje do niej oficjalny norweski dokument poświęcony prawom dziecka i problemowi wykorzystywania seksualnego, zatytułowany "Kiedy Czerwony Kapturek spotyka wilka” (Nar Rodhette Moter Ulver) ${ }^{33}$.

Helga Stipa Madland zwraca uwagę na fakt, że kolejne wersje Czerwonego Kapturka są odzwierciedleniem przemian seksualności kobiecej dokonujących się w społeczeństwie zachodnim. Z jednej strony, za Jackiem Zipem stwierdza, że historia małej dziewczynki wędrującej przez las do babci staje się pretekstem do ukazania męskich niepokojów w obliczu kobiecej seksualności, z drugiej - ich własnych niepokojów seksualnych ${ }^{34}$. H.S. Madland ukazuje tranzycję w sposobie portretowania Czerwonego Kapturka, który w przekazach ustnych był „zdrową, pewną siebie, wiejską dziewczyną, całkiem zdolną do zadbania o siebie i wilka". Natomiast, w opowieściach

${ }^{30}$ G. Mistral, Czerwony Kapturek, przekł. K. Rodowska, Warszawa 2017.

${ }^{31}$ B. Bettelheim, The enchantment, s. 169.

${ }^{32}$ F. Mackintosh, Babes in the Bosque: Fairy Tales in Twentieth-Century Argentine's Women's Writing, [w:] Fairy Tales and Feminism; New Approaches, red. Donald Haase, Detroit 2004, s. 160.

33 S. Beckett, Red Riding Hood for All Ages, s. 22.

${ }^{34}$ H.S. Madland, The Trails and Tribulations of Little Red Riding Hood by Jack Zipes. Review, The Modern Language Journal, 1984 Autumn, 68, 3, s. 278. 
braci Grimm i Ch. Perraulta stał się „miłą, zepsutą, łatwowierną i bezsilną” dziewczynką ${ }^{35}$.

W ten sposób zwraca ona uwagę na dominujące w późniejszych wersjach tej postaci takie cechy, jak uległość, bezsilność, zagubienie, a także na rolę wprowadzonego do bajki przez braci Grimm myśliwego, który uosabia silną i dominującą wersję męskości ${ }^{36}$. Zdaniem B. Bettelheima, wprowadzenie do bajki postaci myśliwego miało na celu ukazanie dwoistej natury mężczyzny, który z jednej strony jest „,samolubny, aspołeczny, gwałtowny i potencjalnie destruktywny", z drugiej - empatyczny, troskliwy i chroniący ${ }^{37}$.

W tradycji psychoanalitycznej istnieją różnorodne odczytania Czerwonego Kapturka. Feona Attwood uważa, że łączy je przekonanie o podstawowym znaczeniu ukrytym w tekście: „dziecięcym pożądaniu do starszego mężczyzny, podszyte strachem o pochłonięcie lub przytłoczenie jego postacią". Zarówno Freud, jak i Bettelheim wskazują tu na kompleks edypalny, włączający strach przed ojcem z jednoczesnym strachem przed ukaraniem za odczuwanie pożądania wobec niego. Bettelheim uznaje także, że istotą bajki jest pragnienie bycia uwiedzioną. Krytykująca te podejścia jako mizoginistyczne, Attwood analizuje Czerwonego Kapturka w kontekście paraboli gwałtu ${ }^{38}$. W jednym z nich postać wilka połykającego żywe istoty ludzkie uznaje się za symbol zazdrości o ciążę, a kamień zaszyty w jego brzuchu jako symbol bezpłodności.

W innej, przytoczonej przez Marię Tatar, interpretacji psychoanalitycznej postać wilka jest projekcją niegodziwości Czerwonego Kapturka i uosabia „ludzkie pożądanie, zachłanność oralną, agresję i pożądanie seksualne”39.

Z kolei, w interpretacji Ericha Fromma (The Forgotten Language) butelka napoju niesiona przez główną bohaterkę w koszyczku jest symbolem dziewictwa. Następnie, czerwień kapturka jest dla niego symbolem menstruacji, która czyni dziewczynkę dojrzałą kobietą zdolną do prokreacji ${ }^{40}$.

Feona Attwood w artykule „Kto się boi Czerwonego Kapturka” zwraca uwagę na swoistą niestabilność/rozmycie się ról płciowych głównych bohaterów. Jej zdaniem, istotą opowieści jest strach mężczyzn przed siłą, która drzemie w kobiecej seksualności. Czerwony Kapturek to, w interprtacji Feony Attwood, odważna dziewczynka, która nie boi się iść sama do lasu, a jej kobieca uroda, wraz z rzucającym się w oczy czerwonym kapturkiem i pelery-

\footnotetext{
35 Tamże.

36 Tamże.

37 S. Bettelheim, The enchantment, s. 172.

38 F. Attwood, Who is Afraid of, s. 96.

${ }^{39}$ M. Tatar, The Hard Facts of the Grimm's Fairy tales, s. 41.

40 S.L. Beckett, Red Riding Hood for All Ages, s. 45.
} 
ną, połączona jest z siłą, która tradycyjnie kojarzy się z męskością. Ponadto, zwraca ona uwagę, iż wilk przebiera się w strój babci i choć jest męski, to zapraszając dziewczynkę do łóżka, zachowuje się w kobiecy sposób. W końcu, myśliwy rozcinając brzuch wilka, przywodzi na myśl akuszerkę odbierającą poród ${ }^{41}$.

\section{Zakończenie}

Nikt by nie założył, że pozornie banalny tekst bajki może być odczytany i interpretowany na różnorodne, sprzeczne sposoby. Mamy, jak gdyby, tutaj do czynienia z postmodernistyczną śmiercią autora i prymatem czytelnika/ interpretatora. Niekiedy czytając różnorodne wersje Czerwonego Kapturka, mam wrażenie, że bajki jako takiej nie ma, że są tylko znaczenia nadawane przez umysł, wzrok czytelnika. Wersja krytyczna, wersja psychoanalityczna, marksistowska, postmodernistyczna, feministyczna. W permanentnej dekonstrukcji interpretacja stała się celem w sobie i nic już nie ma jednoznacznego znaczenia. Oryginalne słowo jest podatne na reinwersję, rekonstrukcję, rekonceptualizację. Autorstwo traci na znaczeniu, a tekst rozsypuje się niczym rozbite zwierciadło na tysiące fragmentów, przy czym ich złożenie w jednoznaczny obraz nigdy nie jest możliwe. Czy Czerwony Kapturek był infantylną dziewczynką, ofiarą gwałtu, czy przemyślną uwodzicielką?

Muszę jednak dodać na zakończenie, że mój tekst stanowi tylko głos w akademickiej dyskusji na temat symboliki Czerwonego Kapturka. Uważam przy tym jednoznacznie, że dyskusje te są do pewnego stopnia tylko akademickie i pozostają bez większego związku z praktyką wychowawczą. Ale tak czy inaczej warto je podejmować.

\section{BIBLIOGRAFIA}

Attwood F., Who is Afraid of Little Red Riding Hood. Male Desire, Phantasy and Impersonation in the Telling of the Fairytale, Thamyris. Mythmaking From Past to Present, 1999, 6, 1.

Baker J.N., Little Red Riding Hood, 1827, [w:] W.E. Burton, The Cyclopedia of Wit and Humor, 1858.

Beckett S.L., Recycling Red Riding Hood, New York 2002.

Beckett S.L., Red Riding Hood for All Ages. An Fairy-Tale Icon in Cross-Cultural Contexts, Detroit 2008.

Bettelheim B., Little Red Cap and the Pubertal Girl, [w:] Little Red Riding Hood: A Casebook, Ed. A. Dundes, Madison, WI: 1989.

${ }^{41}$ F. Attwood, Who is Afraid of Little Red Riding Hood. Male Desire, Phantasy and Impersonation in the Telling of the Fairytale, Thamyris. Mythmaking From Past to Present, 1999, 6, 1, s. 100-101. 
Bettelheim B., The Uses of Enchantment. The Meanings and Importance of Fairy Tales, London 1991.

Carruthers A., Little Red Riding Hood - And Others Girls Who Hot Lost in the Woods, Warwickshire 2015 - wykorzystano przedruk książki bez stron.

Chalou B., A postmodern analysis of the Little Red Riding Hood Tale, Lewiston, NY: 2002.

Dahl R., Little Red Riding Hood and the Woolf, adres internetowy: https:/ / ace.home.xs4all. $\mathrm{nl} /$ Literaria/Txt-Dahl.html

Delarue P., The Story of Grandmother, [w:] Little Red Riding Hood. A Casebook, Ed. A. Dundes, Madison 1989.

Dundes A. (Ed.), Little Red Riding Hood: A Casebook, Madison 1989.

Girl Culture. An Encyclopedia, vol. 1, Eds. C. Mitchell, J. Reid-Walsh, London 2007.

Gromkowska-Melosik A., Power Girl i kontrowersje wokót (pop)kulturowej emancypacji kobiet wspótczesnych, [w:] Kultura popularna. Konteksty teoretyczne i społeczno-kulturowe, red. A. Gromkowska-Melosik, Z. Melosik, Kraków 2010.

Grover Thurber J., The Little Girl and the Wolf, Otago German Studies, 1998, 10, adres internetowy: https://otagogermanstudies.otago.ac.nz/ogs/issue/view/13

Gunning M., Not Before Bed, https://www.januarymagazine.com/artcult/littlereduncloaked.html

Husing G., "Is Little Riding Hood" a Myth? [w:] Little Ride Riding Hood. A Casebook, Ed. A. Dundes, Madison 1989.

Mackintosh F., Babes in the Bosque: Fairy Tales in Twentieth-Century Argentine's Women's Writing, [w:] Fairy Tales and Feminism; New Approaches, red. Donald Haase, Detroit 2004.

Madland H.S., The Trails and Tribulations of Little Red Riding Hood by Jack Zipes. Review, The Modern Language Journal, 1984 Autumn, 68, 3.

Mistral G., Czerwony Kapturek, przekł. K. Rodowska, Warszawa 2017.

Orenstein C., Little Red Riding Hood Uncloaked: Sex, Morality, and the Evolution of a Fairy Tale, New York 2002.

Perrault Ch., Bajki Babci Gąski, przekł. H. Januszewska, Wrocław 1993.

Reklama ChanelNo.5zudziałem Estelli Warren, adres internetowy: https:/ / www.youtube. $\mathrm{com} /$ watch? $\mathrm{v}=\mathrm{z} 5 \mathrm{MHa} 1 \mathrm{CtNEI}$

Tartar M., The Hard Facts of the Grimm's Fairy Tale, New Jersey 2003.

The Trials and Tribulations of Little Red Riding Hood, Ed. J. Zipes, New York 1993.

Zipes J., The Trials and Tribulations of Little Red Riding Hood, New York 1993. 